\title{
Article \\ Genetic Variants of Matrix Metalloproteinase and Sepsis: The Need Speed Study
}

\author{
Nicola Fiotti ${ }^{1, *(D)}$, Filippo Mearelli ${ }^{1}\left(\mathbb{D}\right.$, Filippo Giorgio Di Girolamo ${ }^{1,2}$, Luigi Mario Castello $^{3}(\mathbb{D}$, \\ Alessio Nunnari ${ }^{1}$, Salvatore Di Somma ${ }^{4}$, Enrico Lupia ${ }^{5} \mathbb{D}$, Efrem Colonetti ${ }^{6} \mathbb{D}$, Maria Lorenza Muiesan ${ }^{6}$, \\ Giuseppe Montrucchio $^{5}$, Carlo Giansante ${ }^{1}$, Gian Carlo Avanzi ${ }^{7}$ and Gianni Biolo ${ }^{1}$ (D)
}

1 Unit of Internal Medicine, Department of Medical Surgical and Health Sciences, University of Trieste, 34149 Trieste, Italy; filippome@libero.it (F.M.); fgdigirolamo@units.it (F.G.D.G.); alessionunnari@gmail.com (A.N.); giansant@units.it (C.G.); biolo@units.it (G.B.)

2 SC Assistenza Farmaceutica, Cattinara Hospital, Azienda Sanitaria Universitaria Integrata di Trieste, 34149 Trieste, Italy

3 Department of Translational Medicine, Università del Piemonte Orientale, Internal Medicine, A.O. "Santi Antonio e Biagio e Cesare Arrigo", 15121 Alessandria, Italy; luigi.castello@med.uniupo.it

4 Unit of Emergency Medicine, Department of Medical Surgery Sciences and Translational Medicine, University "Sapienza” of Rome, 00185 Roma, Italy; salvatore.disomma@uniroma1.it

5 Unit of Emergency Medicine, Department of Medical Sciences, University of Turin, 10124 Torino, Italy; enrico.lupia@unito.it (E.L.); giuseppe.montrucchio@unito.it (G.M.)

6 Unit of Internal Medicine, Department of Clinical and Experimental Sciences, University of Brescia, 25121 Brescia, Italy; colonetti@gmail.com (E.C.); marialorenza.muiesan@unibs.it (M.L.M.)

7 Department of Translational Medicine, Università del Piemonte Orientale, Via Solaroli 17, 28100 Novara, Italy; giancarlo.avanzi@uniupo.it

* Correspondence: fiotti@units.it; Tel.: + 39-040-399-3226

check for updates

Citation: Fiotti, N.; Mearelli, F.; Di Girolamo, F.G.; Castello, L.M.; Nunnari, A.; Di Somma, S.; Lupia, E.; Colonetti, E.; Muiesan, M.L.; Montrucchio, G.; et al. Genetic Variants of Matrix Metalloproteinase and Sepsis: The Need Speed Study. Biomolecules 2022, 12, 279. https:// doi.org/10.3390/biom12020279

Academic Editor: Raffaele Serra

Received: 2 January 2022

Accepted: 4 February 2022

Published: 9 February 2022

Publisher's Note: MDPI stays neutral with regard to jurisdictional claims in published maps and institutional affiliations.

Copyright: (C) 2022 by the authors. Licensee MDPI, Basel, Switzerland. This article is an open access article distributed under the terms and conditions of the Creative Commons Attribution (CC BY) license (https:// creativecommons.org/licenses/by/ $4.0 /)$.

\begin{abstract}
Many causal mechanisms in sepsis susceptibility are largely unknown and the functional genetic polymorphisms (GP) of matrix metalloproteinases (MMPs) and their natural tissue inhibitor of MMPs (TIMP1) could play a role in its development. GPs of MMPs and TIMP (namely MMP-1 rs1799750, MMP-3 rs3025058, MMP-8 rs11225395, MMP-9 rs2234681, and TIMP-1 rs4898) have been compared in 1058 patients with suspected sepsis to assess the association with susceptibility and etiology of sepsis. Prevalence of MMP8 rs11225395 G/G genotype was higher in sepsis patients than in those with non-infective Systemic Inflammatory Reaction Syndrome (35.6 vs. 26\%, hazard ratio, HR 1.56, 95\% C.I. 1.04-2.42, $p=0.032)$. G/G patients developed less hyperthermia $(p=0.041)$, even after stratification for disease severity $(p=0.003)$. Patients carrying the 6A allele in MMP3 rs3025058 had a higher probability of microbiologically-proven sepsis (HR 1.4. 95\%C.I. 1.01-1.94, $p=0.044$ ), particularly when due to virus (H.R. 2.14, 95\% C.I. 1.06-4.31, $p=0.046$ ), while MMP-1 G/G genotype patients carried a higher risk for intracellular bacteria (Chlamydia, Mycoplasma, and Legionella, H.R. 6.46, 95\% C.I. 1.58-26.41, $p=0.003$ ). Neither severity of sepsis at presentation, nor 30-day mortality were influenced by the investigated variants or their haplotype. MMP8 rs11225395 G/G carriers have lower temperature at presentation and a more than $50 \%$ increased susceptibility to sepsis. Among patients with sepsis, carriers of MMP1 rs1799750 G/G have an increased susceptibility for intracellular pathogen infections, while virus serology is more often positive in those with the MMP3 rs3025058 A/A genotype.
\end{abstract}

Keywords: matrix metalloproteinases polymorphism; sepsis; SIRS; fever; hyperthermia

\section{Introduction}

Sepsis, the invasion of microorganisms inducing a generalized inflammatory response, is a major cause of death and permanent disability in Western countries and worldwide [1]. Its occurrence and outcomes reflect the balance between, on one side, the invading capacities of the pathogen, and on the other, mechanical and immune (innate and acquired) 
mechanisms. Both defense mechanisms have key players in matrix metalloproteinases (MMPs) and their inhibitors (tissue inhibitors of matrix metalloproteinases, TIMPs) [2]. MMPs are calcium and zinc-dependent proteolytic enzymes that can be membrane-bound or soluble (secreted), which are able to degrade all components of the extracellular matrix, thereby favoring cell migration within tissues and enhancing the availability of growth factors bound to the matrix. Over the years, many non-structural and intracellular targets of MMPs have been identified, thus expanding their potential role in immune modulation [3-5] and other cellular functions [6].

MMP activities are tightly regulated through epigenetic, transcriptional, and posttranscriptional modulation of gene expression, proteolytic activation, post-translational modifications, and extracellular inhibition [7]. Among these, functional polymorphisms influence gene expression and activity and might therefore control the pathogen invasion process, thus influencing susceptibility, clinical presentation, and likely the outcomes of sepsis. Inhibition and clearance of these MMPs are performed by specific inhibitors (tissue inhibitor of metalloprotease, TIMP 1-4), which, in turn, undergo regulation of its expression by genetic polymorphisms. At present, knowledge on the role of MMP/TIMP polymorphisms has been derived from small studies mainly focused on the prognostic value of these variants. Nonetheless, their differential expression might identify specific pathways for the susceptibility and presentation of sepsis compared to other inflammatory non-septic conditions.

The role of MMPs in sepsis has already been addressed in experimental and clinical conditions, although clinical investigation has mainly focused on plasma levels [8-10]. A major limitation of this type of approach is that plasma MMP or TIMP concentration fluctuates in sepsis according to the stage of the disease, and each MMP might have different timing in appearance, some being immediately released by activated neutrophils (e.g., MMP-8 and MMP-9) [11] while others are expressed and released by inflamed tissues over a different time period [12]. In this context, functional genetic variants would enable us to estimate the in vivo effects of a different expression of MMP or TIMP within tissues free from the timing of the sample collection. In the choice of MMP/TIMP and their genetic variants, we started from MMPs with increased/decreased expression (or plasma levels) during sepsis [13], with functional genetic variants and adequate allelic frequency and, when available, connected with expression pathways known to be activated during sepsis, (e.g., ets or NF-kB) [14-16].

In the present study, we investigated the association of five functional polymorphisms of MMP-1 rs1799750, MMP-3 rs3025058, MMP-8 rs11225395, MMP-9 rs2234681, and TIMP-1 rs4898 with clinical presentation of Systemic Inflammatory Response Syndrome (SIRS), sepsis susceptibility, etiology, and survival in a cohort of patients from the Need Speed study.

\section{Materials and Methods}

\subsection{Patients and Study Design}

The population study was selected from the cohort of the Need Speed study, an Italian multicenter study on the diagnosis of sepsis, the study design and results of which have already been published $[17,18]$. Briefly, patients admitted to ER or medical wards with at least two SIRS criteria [19] and suspicion of sepsis were enrolled. Exclusion criteria were minor age and refusal to participate to the study. Each patient or legal representative signed a written informed consent form to participate in the study. Blood samples were taken at admission and diagnostic workout carried out according to the principles of good clinical practice and blinding of the results of the research. A flowchart of the study is shown in Supplementary Figure S1. Comorbidities, severity of condition, final diagnosis, and 30-day survival were considered. Each researcher in charge of the patient conveyed the final diagnosis and the development of complications. In order to balance different inter-researcher interpretations, an independent committee (i.e., colleagues involved in the study but not in clinical workout of the specific patient) validated the diagnosis and complications. Disagreements between doctors in charge and the committee were discussed 
and a final diagnosis was formulated for the study analysis. All of the above evaluations (by the researcher and by the committee) were blinded to the results of the research and genetic test. The final diagnoses of each patient were grouped into three categories: definite sepsis; non-infective SIRS, when a definite diagnosis alternative to sepsis was posed; and debatable, when no definite or exclusive evidence of sepsis or Ni-SIRS was reached. In turn, sepsis patients were divided in either microbiologically proven, when clinical course plus culture test (from blood, urine, sputum, pleural liquid, cerebrospinal fluid, abscess material), serology, PCR based amplification of pathogen genetic material, immunofluorescence-based antigen detection, identified one or more microorganisms likely to be causative of sepsis, or clinical sepsis when imaging and/or clinical course were suggestive but with negative or uncertain culture test. In the case of more pathogens observed in the same patients, only those microorganisms alleged to contribute to sepsis were considered for further analysis.

All patients with a definite diagnosis were included to assess susceptibility to sepsis, while only those with culture or serology positive workout were investigated for the association of MMP variants with susceptibility to a specific pathogen. Patient outcome considered for association analysis were 30-day survival. The present sub-analysis was conducted on all patients providing the genetic material.

The study complies with the Declaration of Helsinki and was approved by the Ethical Committee of each institution participating in the study.

\subsection{DNA Extraction and Polymorphism Analysis}

DNA was extracted from a venous blood sample with a suitable extraction kit on Maxwell $16^{\mathrm{TM}}$ (both products from Promega Italia) according to the manufacturer's instructions. For MMP-1 rs1799750 and MMP-3 rs3025058, which are ins/del variants and MMP-9 rs2234681, which is a variable number of tandem repeats (VNTR, 13-26 CA repeats around -90 from transcription start), the amplicon size (informative of genotype) was assessed through capillary electrophoresis according to the methods already published [20]. The repeats in the MMP9 rs2234681 allele were grouped in those with 21 or less repeats or 22 or more, according to a previous work [21]. For MMP-8 rs11225395 and TIMP-1 rs 4898, which are substitution variants, commercial kits (Taqman technology, catalog number C 1,366,493 20 and C 11,175,659 10, respectively, from Lifetechnologies) were assessed in Real-Time Biorad according to the manufacturer's instructions.

Patients were genotyped by expert personnel at the University of Trieste blinded to any clinical data except for gender during (X-linked) TIMP-1 genotyping. Results of such variants were analyzed and reported as carriers (or not) of the T(A) allele, independent of the gender of the carrier, consistent with a previous paper [22].

Hardy-Weinberg (HW) equilibrium and Linkage disequilibrium (for MMP-1, MMP-8, and MMP-3, $\mathrm{D}^{\prime}$ ) as well as haplotype analysis were determined using the online calculator available at https: / / www.snpstats.net/ (accessed on 20 December 2021) [23]. In MMP-9 rs2234681, alleles were considered as short and long and the HW calculated accordingly [24]. For the X-linked TIMP-1 gene, HW was assessed for female patients and allelic frequencies between the two sexes were compared.

Genetic material was handled according to the Italian guidelines for the treatment of genetic material (General Authorization No. 8/2013 for the Processing of Genetic Data, from the "Garante per la protezione dei dati personali", accessible at http: / / www.garanteprivacy. it/web / guest/home/docweb / / docweb-display / docweb / 2818993 (accessed on 20 December 2021).

\subsection{Statistical Analysis}

Categorical or continuous variable data are reported as the number of observations and prevalence or median and interquartile (IQR) values, respectively. Associations among categorical variables were investigated with the chi-square $\left(\chi^{2}\right)$ test, hazard ratio and 95\%CI. For continuous variables, the skewed data distribution of some of these called for non-parametric statistics. Consequently, all comparisons of the continuous variables 
among categorical variables were investigated using the Mann-Whitney or Kruskal-Wallis test, and linear correlation was analyzed by the Spearman's Rho ranking test. Survival analysis was performed with the Kaplan-Maier test and a comparison within the categorical variables was obtained through the logarithmic rank test (Mantel Cox). Unconditional binary logistic regression analysis was used to examine the constructed $95 \%$ confidence intervals (95\% CIs) and hazard ratios (HRs), for genetic variants in the final diagnosis of sepsis together with variants used for previous work [17], or for specific diagnosis of viral or intracellular pathogen diagnosis for the codominant, dominant, recessive, and sovradominant models. Association of genetic variables was conducted assuming a codominant, dominant, recessive, or over-dominant model [25]. Haplotype analysis was conducted to investigate the interaction of polymorphisms in association with the clinical variable investigated. Comparison of genotypes and genotype/haplotype interaction were based on the comparison of HR and 95\% CI.

A two tailed $p$-value less than 0.05 or HR 95\%CI not encompassing the "1.0" value was considered statistically significant. All statistical analysis was conducted with SPSS 21.0 (Statistical Package for Social Sciences, SPSS Inc., Chicago, IL, USA).

\section{Results}

\subsection{Population and MMP/TIMP Polymorphism}

In total, 1058 patients were analyzed in the present sub-study. Among these, a definite diagnosis was reached in 939 patients: 127 non infective SIRS (Ni-SIRS) and 812 sepsis, leaving debatable diagnosis (SIRS cases that could not be robustly characterized as infected) in the remaining 119. Clinical and laboratory data were complete in more than $99 \%$ of cases. Genotyping was successful in $99.5 \%$ of patients overall with few patients not fully genotyped (namely 6, 7, 3, 3, and 8 patients for MMP-1, -3, -8, -9, and TIMP-1, respectively). HW equilibrium was maintained for MMP1, -3 , and -9 ( $p=0.99,0.354,0.181$, respectively) and for TIMP-1 female patients, ( $p=0.857$, T allelic frequency of 0.57 and 0.566 in the female and male sex, respectively). HW equilibrium for MMP8 was not demonstrated $(p=0.000029)$ with increased heterozygosity. Furthermore, HW equilibrium was reevaluated in patients with a definite diagnosis, with no remarkable differences from the whole population. Consistently, for MMP-8 rs11225395, HW was not confirmed in all groups of patients $(p=0.02,0.0022$, and 0.039 for non-infective SIRS, sepsis, and undefined patients, respectively). Linkage disequilibrium between MMP-1 rs1799750 and MMP-8 rs11225395 was demonstrated (D stat $\left.=0.0241, D^{\prime}=0.12 r=0.0992 p=<0.0001\right)$. No difference in genetic frequencies could be detected comparing the different centers contributing to the study (all $p>0.05)$. Patients' general characteristics, SIRS criteria, clinical variables at presentation, and severity and comorbidity indexes are reported in Table 1 grouped according to the final diagnosis.

The association of MMP polymorphisms with features of presentation were examined independent of final diagnosis.

\subsection{MMP/TIMP Genotype and Sepsis Susceptibility}

The prevalence of different genotypes was compared only in patients with definite diagnosis (i.e., sepsis and non-infective SIRS). Allelic and genetic prevalence are reported in Figure 1 and Table S1, Supplementary Materials. Cross tabulation of genetic prevalence was marginally significant only for MMP-8 (codominant model), although MMP-8 G/G genotype (recessive model) was more prevalent in sepsis patients than in non-infective SIRS patients (35.6 vs. $26 \%$ ) with an increase in risk of $58 \%$ (95\%CI 1.04-2.42). 
Table 1. Demographic, clinical presentation, comorbidities, and clinical severity of the patients, according to the final diagnosis. SIRS criteria and comorbidities are described as positive/negative finding for the condition, while continuous variables are the median and, in parentheses, interquartile range. $p=p$ values of Kruskal-Wallis or $\chi 2$ square test, $\mathrm{WBC}=$ white blood cells.

\begin{tabular}{|c|c|c|c|c|}
\hline & Ni-SIRS (127) & Sepsis (812) & Debatable (119) & $p$ \\
\hline Male/female & $66 / 61$ & $426 / 386$ & $52 / 67$ & 0.201 \\
\hline Age & $72(59-84)$ & $81(72-87)$ & $78(71-87)$ & 0.000 \\
\hline \multicolumn{5}{|l|}{ SIRS criteria } \\
\hline Hyperthermia & $20 / 107$ & $389 / 423$ & $33 / 86$ & 0.0000 \\
\hline Hypothermia & $4 / 123$ & $33 / 779$ & $3 / 116$ & 0.658 \\
\hline Leukocytosis & $55 / 72$ & $459 / 353$ & $77 / 42$ & 0.002 \\
\hline Leukopenia & $4 / 123$ & $30 / 782$ & $7 / 112$ & 0.464 \\
\hline Tachycardia & $112 / 15$ & $608 / 204$ & $95 / 24$ & 0.003 \\
\hline Tachypnea & $98 / 29$ & $615 / 197$ & $81 / 38$ & 0.165 \\
\hline Immature leukocytes & $0 / 127$ & $3 / 809$ & $0 / 119$ & 0.634 \\
\hline \multicolumn{5}{|l|}{ Clinical presentation } \\
\hline Breathing rate & $22(20-26)$ & $24(20-27)$ & $22(20-26)$ & 0.301 \\
\hline Heart rate, & $103(96-110)$ & $100(90-110)$ & $100(90-108)$ & 0.001 \\
\hline Temperature & $36.5(36-37.1)$ & $37.6(36.5-38.2)$ & $36.7(36-37.8)$ & 0.000 \\
\hline WBC count & $10.8(7.5-14.5)$ & $12.8(9.2-16.7)$ & $13(9.4-15.8)$ & 0.001 \\
\hline \multicolumn{5}{|c|}{ Comorbidities, severity and scores } \\
\hline $\begin{array}{l}\text { Charlson comorbidity } \\
\text { index }\end{array}$ & $2(1-5)$ & $3(1-5)$ & $3(2-5)$ & 0.008 \\
\hline SOFA Score & $2(1-3)$ & $3(2-4)$ & $3(2-4)$ & 0.000 \\
\hline Apache II Score & $10(7-12)$ & $12(9-15)$ & $11(9-14)$ & 0.000 \\
\hline SAPS Score & $36(27-40)$ & $37(34-43)$ & $36(34-42)$ & 0.000 \\
\hline
\end{tabular}

Haplotype analysis was conducted to observe additive diagnostic efficacy of MMP-8 rs11225395, MMP-9 rs2234681, and TIMP-1 rs4898 haplotype over the MMP-8 genotype. No advantage was demonstrated for haplotype analysis of MMP-8 and MMP-9 (global haplotype association $p$ value $=0.24$ ) and when TIMP-1 rs4898 was considered as a covariate (interaction $p$ value $=0.2$ ).

\subsection{Clinical Presentation and MMP-8 rs11225395}

Further investigation was carried out on MMP-8 polymorphism and its association with clinical presentation. SIRS criteria between Ni-SIRS and sepsis are summarized in Table 1 and their comparison according to MMP-8 genotype for Ni-SIRS and sepsis is reported in Table 2.

In order to rule out the effect of possible confounders in the comparison between Ni-SIRS and septic patients, the same comparisons were carried out after stratification for age and disease severity (SOFA, Charlson, Apache II, and SAPS score). This yielded a group of 91 patients, whose results are reported in Figure 2 and Supplementary Table S2. After standardization, body temperature at admission was the only SIRS criteria remaining higher in septic patients and different according to MMP8 genotype. Compared to the G/G genotype, A carriers had an increased risk for hyperthermia across the whole group and in the stratified septic patients (HR 4.4, 95\%CI 1.7-11.4, $p=0.0024$ and 5.8, 95\%CI 1.9-18.2, $p=0.0024$, respectively). Breathing rate showed a statistically weak paradoxical pattern, particularly with a higher rate of A carriers in Ni-SIRS patients. 


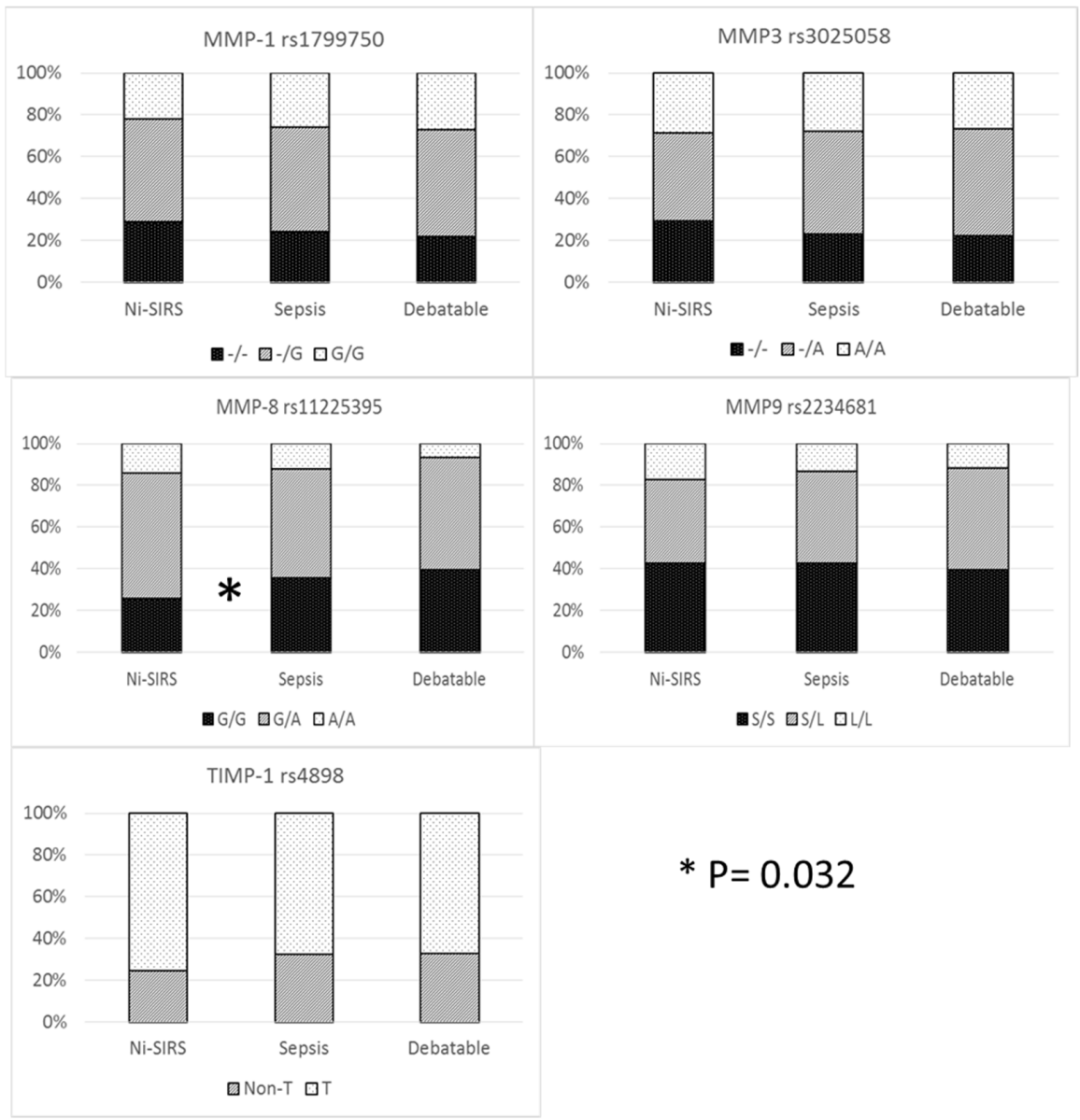

Figure 1. MMP/TIMP genetic variables and diagnosis.

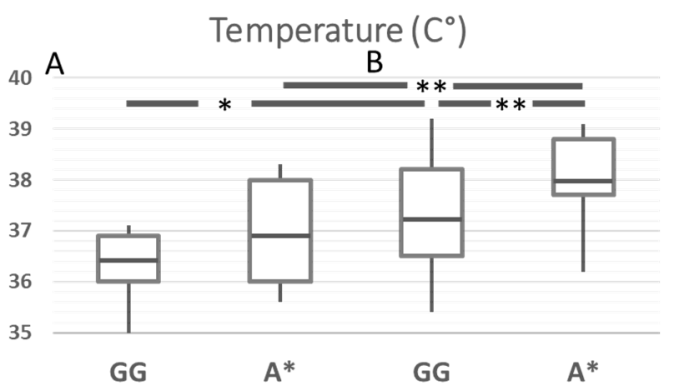

White blood cells count $\left(* 10^{3} / \mathrm{mm}^{3}\right)$

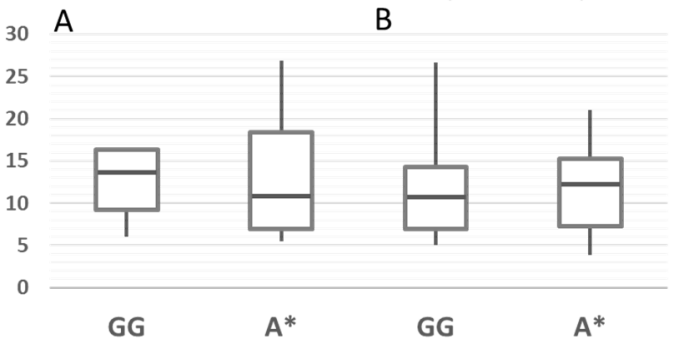

Heart Rate (beats per minute)

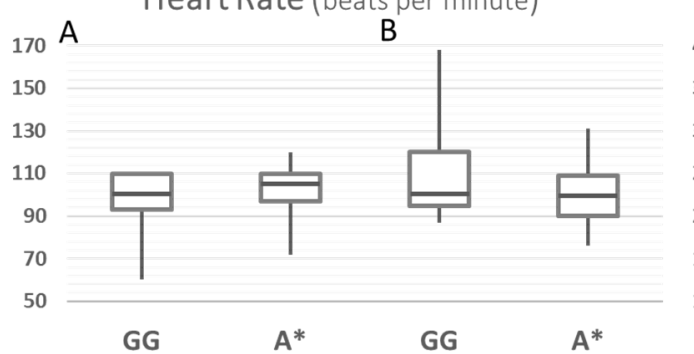

Breathing Rate (breaths per minute)

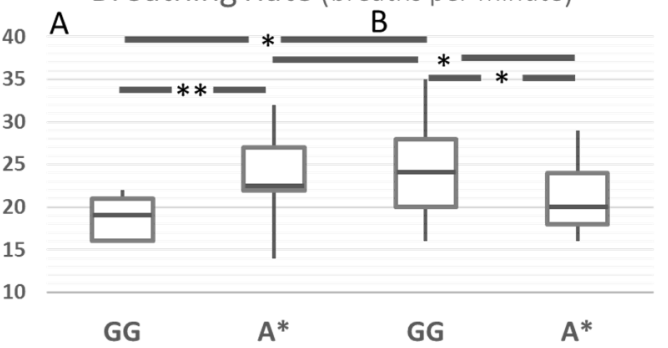

Figure 2. SIRS criteria according to MMP8 rs11225395 polymorphism in patients with Ni-SIRS (A) and sepsis (B) standardized for diabetes, age, and severity (SOFA score). ${ }^{* *}=p<0.01,{ }^{*}=p<0.05$. 
Table 2. Clinical presentation of sepsis and MMP8 rs11225935 (unstandardized). Comparisons were carried out with $\chi^{2}$ test or Mann-Whitney, according to the variable considered, and $p$ values are reported on the right columns. $p$ values legend: Ni-SIRS and Seps = comparison of SIRS criteria according to MMP-8 genotypes within each group (Ni-SIRS and Sepsis, respectively), GG and $\mathrm{A}^{*}=$ comparison of SIRS criteria within a specific genotype (GG or A carrier) across the different groups of patients.

\begin{tabular}{cccccccccc}
\hline & \multicolumn{2}{c}{ Ni-SIRS } & \multicolumn{2}{c}{ Sepsis } & \multicolumn{3}{c}{$p$ values } \\
\hline & GG $(\boldsymbol{n}=\mathbf{3 3})$ & $\mathbf{A}^{*}(\boldsymbol{n}=\mathbf{9 4})$ & $\mathrm{GG}(\boldsymbol{n = 2 8 9 )}$ & $\mathbf{A}^{*}(\boldsymbol{n = 5 2 0})$ & Ni-SIRS & Seps & GG & $\mathbf{A}^{*}$ \\
\hline Hyperthermia & $5 / 28$ & $15 / 79$ & $124 / 165$ & $262 / 258$ & 0.913 & 0.041 & 0.002 & 0.000 \\
\hline Hypothermia & $1 / 32$ & $3 / 91$ & $13 / 276$ & $20 / 500$ & 0.964 & 0.653 & 0.695 & 0.758 \\
\hline Temperature & $36.5(36-37)$ & $36.5(36-37)$ & $37.5(36.5-38)$ & $37.7(36.6-38)$ & 0.981 & 0.247 & 0.000 & 0.000 \\
\hline Leukocytosis & $13 / 20$ & $42 / 52$ & $165 / 124$ & $293 / 227$ & 0.598 & 0.837 & 0.053 & 0.037 \\
\hline Leukopenia & $1 / 32$ & $3 / 91$ & $10 / 279$ & $19 / 501$ & 0.964 & 0.887 & 0.898 & 0.824 \\
\hline WBC count & 10.9 & 10.7 & 12.7 & 12.9 & 0.606 & 0.677 & 0.19 & 0.002 \\
\hline Tachycardia & $30 / 3$ & $82 / 12$ & $229 / 60$ & $377 / 143$ & 0.574 & 0.034 & 0.109 & 0.002 \\
\hline Heart rate & $107(99.113)$ & $(96-110)$ & $100(92-110)$ & $100(90-110)$ & 0.359 & 0.576 & 0.017 & 0.011 \\
\hline Tachypnea & $26 / 7$ & $72 / 22$ & $227 / 62$ & $387 / 133$ & 0.796 & 0.189 & 0.974 & 0.655 \\
\hline Breath rate & $22(20-26)$ & $22(20-26)$ & $24(20-26)$ & $24(20-26)$ & 0.408 & 0.854 & 0.617 & 0.33 \\
\hline Immat. WBC & 0 & 0 & $2 / 287$ & $1 / 519$ & n.a. & 0.262 & 0.632 & 0.67 \\
\hline
\end{tabular}

\subsection{Severity and Diagnosis of Patients with Sepsis}

Among the 812 sepsis patients with available genetic data, there was no association between MMP genetic variants and severity, prognosis, or type of diagnosis, the results of which are reported in Table S3, Supplementary Materials. Comorbidities, assessed with the Charlson Comorbidity Index and severity of condition measured with APACHE II, SAPS, and SOFA score did not differ, according to the genotype. The results are reported in Table S4.

\subsection{Pathogens and Genetic Variants}

A list of isolated microorganisms is reported in Table S5, Supplementary Materials. Within patients with microbiologically proven sepsis, an association between some pathogens and MMP genetic variants was occasionally found, although none could stand the statistical multiple comparisons correction (described in detail in the legend of Table S4, Supplementary Materials. Additionally, some statistical trends (i.e., $p<0.1$ and $>0.05$ ) could also be observed. Collectively, small intracellular bacteria and viruses did not reach statistical significance when analyzed individually, but when grouped, the association with MMP-1 rs1799750 and MMP3 rs3025058, respectively, became strong ( $p=0.004$ for both).

Evaluation of MMP polymorphisms have also been reported when grouping the pathogens according to Gram staining properties (Gram positive or negative), intracellular (atypical) bacteria, viruses, and fungi, amongst others, is reported in Table 3. Hazard ratios associated with diagnosis of a specific class of pathogens is reported as a forest plot in Figure 3. $p=\chi^{2}$ test for all diagnoses. 
Table 3. Genetic variants and groups of pathogens. Legend: a = codominant (- vs. $-G$ vs. GG), $p=0.004 . \mathrm{b}=$ dominant $(-/-\mathrm{G}$ vs. GG) H.R. $6.295 \%$ C.I. $1.5-25.3, p=0.004 . \mathrm{c}=$ codominant (- vs. - G vs. GG) $p=0.004 . \mathrm{d}=$ dominant $(-/-$ G vs. GG), H.R. 7.7 95\%CI 1.5-40.4, $p=0.005$. $\mathrm{e}=$ dominant ( - / A vs. AA), H.R. 0.47 95\% CI 0.23-.94, $p=0.032 . \mathrm{f}=$ T vs. Non-T H.R. 0.21, 95\% C.I. $0.04-1.1 p=0.041$.

\begin{tabular}{cccccc}
\hline & MMP-1 & MMP-3 & MMP-8 & MMP-9 & TIMP-1 \\
\hline & rs1799750 & rs3025058 & rs11225395 & rs2234681 & rs4898 \\
\hline All & $106 / 214 / 107$ & $123 / 194 / 113$ & $48 / 230 / 150$ & $179 / 187 / 62$ & $148 / 279$ \\
\hline Gram+ & $37 / 73 / 30$ & $46 / 59 / 35$ & $15 / 75 / 50$ & $51 / 67 / 22$ & $48 / 92$ \\
\hline Gram- & $59 / 121 / 54$ & $66 / 114 / 57$ & $28 / 129 / 78$ & $104 / 102 / 29$ & $83 / 152$ \\
\hline Intracell & $3 / 0 / 6$ a b & $1 / 4 / 4$ & $1 / 5 / 3$ & $4 / 2 / 3$ & $1 / 8$ \\
\hline Virus & $6 / 19 / 12$ & $9 / 13 / 15 \mathrm{e}$ & $4 / 18 / 15$ & $15 / 14 / 8$ & $11 / 25$ \\
\hline Fungus & $1 / 1 / 5 \mathrm{~cd}$ & $1 / 4 / 2$ & $0 / 3 / 4$ & $5 / 2 / 0$ & $5 / 2 \mathrm{f}$ \\
\hline$p$ & 0.004 & 0.346 & 0.942 & 0.239 & 0.152 \\
\hline
\end{tabular}

MMP1 Dom

MMP1 Rec

MMP3 Dom

MMP3 Rec

MMP1 Dom

MMP1 Rec

MMP3 Dom

MMP3 Rec

MMP1 Dom

MMP1 Rec

MMP3 Dom

MMP3 Rec

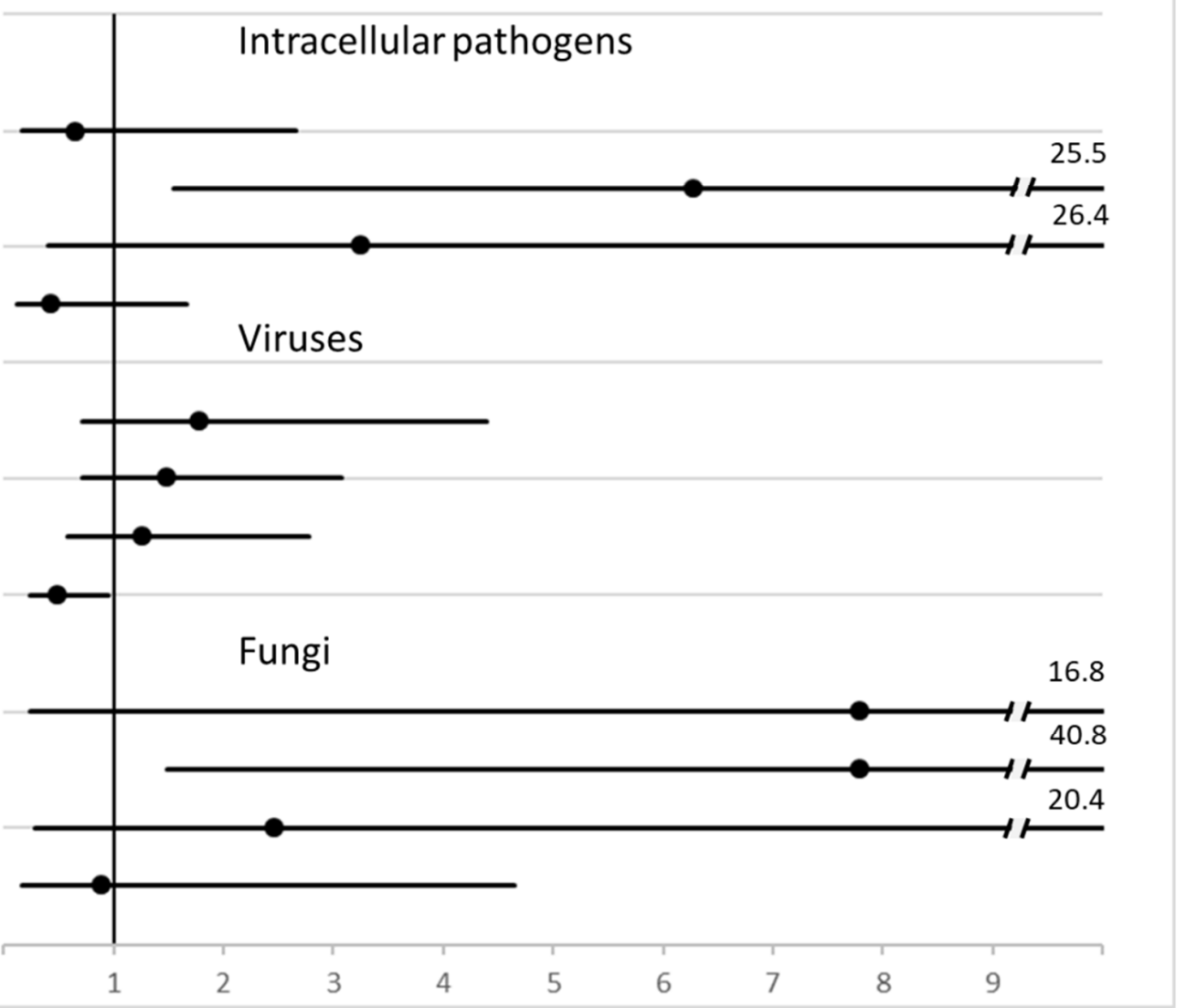

Figure 3. Forest plot of $\mathrm{HR}$ and $95 \% \mathrm{CI}$ of MMP genotype variants and diagnosis of some classes of pathogens. Legend: MMP1 = rs1799750, MMP3 = rs3025058. 


\subsection{Binary Logistic Regression}

To integrate the predictive role of MMP polymorphisms in the diagnosis of sepsis, binary logistic regression considered as the dependent variable the diagnosis of sepsis, sepsis due to virus, or intracellular pathogens and as independent variables, those available at admission (detailed in the Materials and Methods). The results are reported in Table 4.

Table 4. Results of the last step of binary logistic regression for the inference of variables associated with all sepsis or sepsis caused by viruses or intracellular atypical bacteria.

\begin{tabular}{|c|c|c|c|c|c|c|}
\hline & B Value (E.S). & Wald & Sig. & $\operatorname{Exp}(B)$ & \multicolumn{2}{|c|}{ 95\% CI EXP(B) } \\
\hline \multicolumn{7}{|c|}{ All sepsis } \\
\hline TIMP-1 rs4898 T carrier & $-0.590(0.265)$ & 4.937 & 0.026 & 0.555 & 0.330 & 0.933 \\
\hline SOFA Score & $0.227(0.066)$ & 11.908 & 0.001 & 1.255 & 1.103 & 1.427 \\
\hline Age & $0.045(0.007)$ & 38.445 & 0.000 & 1.046 & 1.031 & 1.061 \\
\hline Hyperthermia & $2.079(0.315)$ & 43.496 & 0.000 & 7.997 & 4.311 & 14.834 \\
\hline C Reactive Protein & $0.013(0.002)$ & 41.767 & 0.000 & 1.014 & 1.009 & 1.018 \\
\hline MMP-8 11,225,395 Dominant & $-0.720(0.254)$ & 8.032 & 0.005 & 0.487 & 0.296 & 0.801 \\
\hline Antimicrobial at home & $0.706(0.306)$ & 5.317 & 0.021 & 2.025 & 1.112 & 3.690 \\
\hline Constant & $-2.182(0.706)$ & 9.563 & 0.002 & 0.113 & & \\
\hline \multicolumn{7}{|c|}{ Virus } \\
\hline MMP-3 rs3025058 5A carrier & $-0.838(0.390)$ & 4.613 & 0.032 & 0.433 & 0.201 & 0.929 \\
\hline COPD & $1.086(0.401)$ & 7.352 & 0.007 & 2.963 & 1.351 & 6.498 \\
\hline Moderate/severe kidney disease & $-2.467(1.034)$ & 5.692 & 0.017 & 0.085 & 0.011 & 0.644 \\
\hline Constant & $-1.779(0.325)$ & 29.905 & 0.000 & 0.169 & & \\
\hline \multicolumn{7}{|c|}{ Intracellular atypical bacteria } \\
\hline TIMP-1 rs4898 C carrier & $2.362(0.906)$ & 6.800 & 0.009 & 10.617 & 1.798 & 62.681 \\
\hline Previous myocardial infarction & $2.263(0.816)$ & 7.699 & 0.006 & 9.613 & 1.943 & 47.545 \\
\hline Dementia & $-2.607(1.247)$ & 4.373 & 0.037 & 0.074 & 0.006 & 0.849 \\
\hline MMP-1 rs1799750 & $2.638(0.842)$ & 9.819 & 0.002 & 13.982 & 2.686 & 72.795 \\
\hline Constant & $-9.255(1.985)$ & 21.736 & 0.000 & 0.000 & & \\
\hline
\end{tabular}

Gram positive or negative bacteria as well as fungus sepsis did not show any association with MMP genetic variants as well as having a sepsis by more than one pathogen (data not shown).

\section{Discussion}

The present study reports the associations between MMP-8 rs11225395 G/G genotype and sepsis compared to patients without sepsis and, moreover, of the MMP-1 rs1799750 and MMP-3 rs3025058 genotypes with diagnosis of sepsis due to intracellular pathogens or virus, respectively.

\subsection{MMP-8 and Sepsis}

MMP-8 is mainly expressed in neutrophils or macrophages, while at later stages of acute lung injury, it can be released from mesenchymal cells in the airways [26]. MMP-8 is upregulated in sepsis [27], although laboratory models and molecular biology only show that its presence ensures neutrophil infiltration in response to lipopolysaccharide [28], likely through the degradation of LIX CXC chemokines [29]. This would limit lung inflammation and act as a key mediator in the regulation of innate immunity. Previous evidence that MMP-8 plays a role in sepsis is heterogeneous: in the cecal ligation perforation procedure, 
MMP-8 inhibition increases survival [30] and high plasma values predict sepsis compared with other patients admitted to ICU [10].

MMP-8 rs11225395, a genetic variant substitution at position -799 , has two variants, with the A variant showing a higher mRNA expression [31,32]. The allelic frequency of the A variant in the general population ranges from 18 to $45 \%$, according to the different populations studied, with the highest prevalence in the European and Mexican populations (available at https:/ / www.snpedia.com/index.php/Rs11225395 (accessed on 3 February 2022). This variant has been previously associated with many different conditions such as cancer [33,34], aggressive periodontitis [35], recurrent pregnancy loss [36], and inflammation in atherosclerosis [32]. In all these studies, Hardy-Weinberg was maintained. Our first and somewhat surprising finding is that the HW equilibrium in our study was not maintained, and this independent of final diagnosis and recruiting center. In investigating the role of MMP-8 rs11225395 in sepsis, only one study has evaluated this variant, with negative results $[10,37]$. The relatively small size of the study and the different enrolling criteria might have hidden the association and the deviation from the HW equilibrium. Of note, MMP-1, -3 , and -8 lie around $74 \mathrm{~kb}$ apart on the long arm of chromosome 11 and are in linkage disequilibrium. In our study, only rs 11225395 showed deviance from the HW equilibrium, with a significant increase in heterozygosity. Classically, violation of HWE can be due to technical reasons or selection of the population. Among the former, possible causes are high minor allele frequency, low genotyping rate/success (typically $<98 \%$ ), or insertion/deletion variant [38]. As our genotyping rate was $>99.5 \%$ (using a widely accepted technique) for a substitution variant, only the high prevalence of a minor allele could hypothetically explain the HW violation. The observation that in a sub-sample of 2196 variants with high $(>98 \%)$ genotyping rate, no gain of heterozygosity was detected [38] further challenges this hypothesis. In conclusion, the most reliable reason for $\mathrm{HW}$ violation is patient selection. Indeed, enrolment in the Need Speed study was restricted to subjects developing no less than two signs/findings of systemic inflammation in response to infective or non-infective stimulus (SIRS criteria).

It was then important to detect which of the SIRS criteria could account for such a selection of the population leading to the violation of the HWE of rs11225395. To overcome the differences in the severity of the conditions within different genotype and diagnosis, a stratified population was required. In these stratified patients, hyperthermia, a canonical sepsis indicator, could be a potential determinant of such a violation. In particular, sepsis patients were at higher risk of hyperthermia: carriers of the minor A allele developed around one more Celsius grade of temperature when stratified for final diagnosis and severity of the condition. At a lesser extent, this was also observed in non-infective SIRS. In conclusion, A allele carriers are prone to developing a SIRS criteria such as hyperthermia, but, at the same time, are protected from SIRS condition and, particularly, from sepsis. This hypothesis is corroborated by the linkage disequilibrium of rs11225395 with another MMP-8 genetic variant (rs1940475, lying less than $1 \mathrm{~Kb}$ apart from rs11225395), which has been investigated by infusion of LPS. The pattern (timing and levels) of cytokines and inflammation response was associated with rs1940475 [39] and this adds to the possibility of a genetic regulation of a classical or smoldering inflammatory picture. Being the A "proinflammatory" allele less represented in the septic group, but more prone to develop high body temperature, it should be postulated that fever is a continuously working mechanism for clearing bacteria (and putatively other DAMPS). While the relationship between temperature-related clearance of bacteria by neutrophils has already been observed experimentally $[40,41]$, the relationship between fever and MMP-8 is reported for the first time. Possible pathways involved in this regulation could be EGFR [42] or bradykinin [43], both proteins capable to modulate MMP- 8 activity. Patients able to develop moderate hyperthermia might therefore be protected from the development of sepsis. Consequently, it can also be extrapolated that infections/sepsis by pathogens occur at a higher than expected rate and local MMP8-mediated inflammation prevents spreading of the germ and pathogenicity. 


\subsection{MMP-1 and Intracellular Pathogens}

A second result of the present study is the association between sepsis caused by intracellular pathogens and MMP-1 rs1799750 G insertion. In MMP-1, the insertion of a G base at -1609 creates an ets (erythroblast transformation specific) binding site that increases by around eight times the MMP-1 mRNA expression under inflammatory stimuli [14]. The apparent conclusion is that MMP-1 helps the pathogenicity or susceptibility of intracellular pathogens (i.e., Chlamydia, Mycoplasma, and Legionella). Further analysis is required to explain the molecular mechanisms for such an association.

If MMP-1 triggers susceptibility to intracellular pathogens, a possible mechanism could be the degradation of an (intracellular) antagonist or the enhancement of growth and diffusion of the microorganisms, putatively through remodeling of the extracellular matrix. In line with this hypothesis is that a protease-rich environment enhances the invasive properties of Mycoplasma Hyorhinis [44]. Under a molecular point of view, Mycoplasma triggers NF-KappaB (NF-kB) pathway activation [45] and ets has a coregulatory role in MMP-1 expression [46,47]. NF-kB stimulation has also been observed for Chlamydia [48] and Legionella [49]; in the latter study, moreover, a direct association between in vitro NF-kB expression and in vivo pathogenicity of the different strains could be demonstrated.

An alternative hypothesis is that, in a condition with more than $50 \%$ of patients without identification of a causative agent, MMP-1 could modify some preanalytical or analytical variants, leading to higher prevalence of identification in carriers of the variant accounting for higher expression. Since the diagnosis of these pathogens is based on three completely different techniques (namely, antigen immunofluorescence identification in urine, PCR based genetic material amplification, or antibody title) and none of them is singularly statistically associated to rs $1799750 \mathrm{G}$ insertion, this possibility should receive limited credit.

In conclusion, pathogen-related activation of the NF-kB pathway and MMP-1 rs1799750 G insertion, leading to ets binding in the promoter, could enhance the susceptibility of some patients to intracellular pathogens. Further investigation is required to demonstrate the mechanisms of MMP-1-related susceptibility. The present study suggests that triggering of ets/NF-kB-regulated protease(s) from a class of pathogens due to a limited number of genes might enhance intracellular pathogen invasiveness. Possible outcomes could be the development of novel therapeutic strategies (selective inhibitors of MMP-1 or the development of vaccines). Under the speculative point of view, the present results challenge the hypothesis that immune genetic variants can work independently of the pathogen causing sepsis.

\subsection{MMP-3 and Virus Sepsis}

The last original observation was the doubled risk of viral sepsis in the $5 \mathrm{~A}$ carrier of MMP-3 rs3025058 - /* genotype. Under specific inflammatory conditions, the MMP-3 rs3025058 5A allele (i.e., deletion of $A$ at position -1171) binds one or more nuclear stimulatory proteins (putatively NF-kB and Zinc-binding protein-89), thus increasing gene expression by two to three times [50]. Accordingly, within the human liver infected with $\mathrm{HCV}$, the difference in MMP-3 expression between the 5A and 6A genotype is around ten times [51]. In contrast, the herniated intervertebral disk shows higher expression in 6A carriers [52]. Regardless of the real picture of the expression, in our study, MMP-3 genotype $6 \mathrm{~A}$ was associated with a higher prevalence of viral sepsis, without a prevalent effect of a virus type over the others. Such a genetic variant has not been previously investigated in viral sepsis, while MMP-3 rs522616 ( $<1 \mathrm{~Kb}$ apart from rs3025058) was associated with severity of respiratory syncytial virus infection, but not to susceptibility, with MMP-3 plasma levels doubled in hospitalized cases compared to mild conditions treated at home [53]. It is not clear, thus far, whether MMP-3 expression during virus infection improves its virulence, assists in the development of a chronic disease, or represents a defensive mechanism of the host. Zta, an Epstein Barr virus protein, induces a four-time increase in MMP-3 in vitro expression which, in turn, is essential for cell invasion of the virus [54], 
although, on the other hand, MMP-3 exerts an indirect antiviral effect in macrophages infected with Dengue virus [6]. In this last study, MMP-3 translocates into the nucleus where it activates the NF- $\mathrm{BB}$ p65 subunit, enhancing the antiviral immune response. NF- $\mathrm{B}$ itself enhances the gene expression of MMP-3 [6]. This loop could be further enhanced by functional genetic variants [50] such as rs3025058. At present, therefore, we report the association of virus sepsis diagnosis with a functional genetic variant of MMP-3. Whether this variant also influences, beyond susceptibility, prognosis is still unknown: we can only report a non-significant better prognosis of $5 \mathrm{~A}\left(-/^{*}\right)$ carriers $(100 \%$ survival vs. $77.8 \mathrm{in} \mathrm{A} / \mathrm{A}$, $p=0.147$, data not shown), but the reduced size of this sample does not allow firm conclusions. Further studies focusing on susceptibility and prognosis and MMP-3 variants hold great potential for risk stratification and treatment of many viral conditions, COVID-19 being the most renowned to date [55].

Finally, the possibility that MMP-3 variants modify pre-analytical conditions influencing the results of the microbiological test but not susceptibility, needs to be discussed. Present technology in the diagnosis of virus infection is indirect (i.e., based on $\operatorname{IgM}$ or high titer IgG antibody levels). Such a technique is notoriously resistant to pre-analytical variables, so a genuine biological association of functional genetic variant of MMP3 with virus infection can be bona fide demonstrated.

\subsection{Comments and Limitations}

Among the negative results, the lack of association with the diagnosis of bacterial sepsis needs further speculation. Two hypothesis can be put forward: the first is that some organs can have a different MMP expression. Several studies have shown that MMP genes are indeed upregulated during infection: different Gram-negative bacteria and lipopolysaccharide induce the transcription of MMP genes [56,57] and for the latter, this happens according to an organ- and time-specific mode [58]. Alternatively, a repertoire of the host's proteinases is required only when the pathogen does not have proteases by itself [59].

Other studies have identified other MMP variants as associated with sepsis susceptibility or prognosis: MMP-1, MMP-3, MMP-8, and TIMP-1 variants have already been investigated in sepsis outcome in a few hundred ICU patients with severe sepsis, [10,22,37]. We cannot confirm the associations found in these previous studies: the possible reasons for such a discrepancy could be inclusion criteria, different age of patients, and setting of the studies (ICU vs. ICU plus medical ward). Even when analyzed by the specific class of pathogens causing the sepsis or gender, this association has not been identified (data not shown). A distinguishing factor for the present study is that it includes around one thousand patients and, for certain variants, is the largest study ever performed in sepsis. Study limitations can be found in the lack of plasma levels of the investigated proteases or TIMP-1, and in the limited number of genetic variants considered. Additionally, inclusion criteria in force at the time of the study ruled out of the investigation of patients with less than two SIRS criteria. Inclusion of patients with broader criteria would have provided a wider perspective on sepsis susceptibility and interaction with MMPs/TIMP-1 as well as with the Hardy-Weinberg equilibrium.

\section{Conclusions}

Our study challenges the concept of sepsis as a unique nosological entity, at least when investigating the role of MMP polymorphisms. While the MMP-8 functional variant could influence the inflammatory (innate immunity) response of the host, a role for single MMP variants can be spotted only for simpler pathogens, requiring a contribution of the host to acquire invasive properties through MMP expression. Thus, while bacteria have no association with any of the investigated MMP polymorphisms, intracellular pathogens, viruses, and fungus likely trigger MMP expression from the host. Genetic variants in loci of MMP-1 or -3 promoters binding NF-kB or ets transcription factors could therefore increase susceptibility to sepsis. 
Supplementary Materials: The following supporting information can be downloaded at: https:// www.mdpi.com/article/10.3390/biom12020279/s1, Figure S1: Flowchart diagram of the study, Table S1: Cross tabulation of MMP genetic variables and diagnosis, Table S2: Clinical presentation of sepsis and MMP8 rs11225935 in groups standardized for age and severity (SOFA, Charlson, Apache II, and SAPS score), Table S3: Association of MMP polymorphisms with severity and diagnosis of sepsis, Table S4: Association of MMP/TIMP polymorphisms with comorbidity, and severity scores, Table S5: Microorganisms identified in the population of sepsis patients.

Author Contributions: Conceptualization, N.F. and F.G.D.G.; Methodology, G.B. and F.M.; Validation, F.M., L.M.C., and G.B.; Formal analysis, N.F. and F.G.D.G.; Investigation, F.M., A.N., E.C. and E.L.; Data curation, L.M.C. and C.G.; Writing-original draft preparation, N.F. Writing-review and editing, F.M. and F.G.D.G.; Visualization, A.N.; Supervision, G.C.A., S.D.S., M.L.M., G.M., and G.B.; Project administration, G.B. Funding acquisition, G.B. All authors have read and agreed to the published version of the manuscript.

Funding: This research was funded by Ministero della Salute (Italian Ministry of Health), grant number RF-2011-02348364.

Institutional Review Board Statement: The study was conducted according to the guidelines of the Declaration of Helsinki and approved by the Institutional Review Board of AZIENDA OSPEDALIERO_UNIVERSITARIA “Ospedali Riuniti” di Trieste (protocol code 56/2013, approved on 16 July 2013)."

Informed Consent Statement: Informed consent was obtained from all subjects involved or their legal representatives in the study.

Data Availability Statement: The data presented in this study are available on request from the corresponding author. The data are not publicly available due to privacy reasons.

Acknowledgments: We are indebted to Paola Pitacco for her excellent support in thee genotyping.

Conflicts of Interest: The authors declare no conflict of interest.

\section{References}

1. Nunnally, M.E.; Ferrer, R.; Martin, G.S.; Martin-Loeches, I.; Machado, F.R.; De Backer, D.; Coopersmith, C.M.; Deutschman, C.S.; Antonelli, M.; Hellman, J.; et al. The Surviving Sepsis Campaign: Research priorities for the administration, epidemiology, scoring and identification of sepsis. Intensiv. Care Med. Exp. 2021, 9, 1-26. [CrossRef]

2. Elkington, P.T.; O'Kane, C.M.; Friedland, J.S. The paradox of matrix metalloproteinases in infectious disease. Clin. Exp. Immunol. 2005, 142, 12-20. [CrossRef] [PubMed]

3. Chen, Y.-L.; Li, W.-Y.; Hu, J.-J.; Li, Y.; Liu, G.-M.; Jin, T.-C.; Cao, M.-J. Nucleus-translocated matrix metalloprotease 1 regulates innate immune response in Pacific abalone (Haliotis discus hannai). Fish Shellfish Immunol. 2018, 84, 290-298. [CrossRef]

4. Nascimento, G.G.; Baelum, V.; Sorsa, T.; Tervahartiala, T.; Skottrup, P.D.; López, R. Salivary levels of MPO, MMP-8 and TIMP-1 are associated with gingival inflammation response patterns during experimental gingivitis. Cytokine 2019, 115, 135-141. [CrossRef] [PubMed]

5. Ceron, C.S.; Baligand, C.; Joshi, S.; Wanga, S.; Cowley, P.M.; Walker, J.P.; Song, S.H.; Mahimkar, R.; Baker, A.J.; Raffai, R.L.; et al An intracellular matrix metalloproteinase-2 isoform induces tubular regulated necrosis: Implications for acute kidney injury. Am. J. Physiol. Physiol. 2017, 312, F1166-F1183. [CrossRef] [PubMed]

6. Bassiouni, W.; Ali, M.A.M.; Schulz, R. Multifunctional intracellular matrix metalloproteinases: Implications in disease. FEBS J. 2021, 288, 7162-7182. [CrossRef]

7. Madzharova, E.; Kastl, P.; Sabino, F.; Keller, U.A.D. Post-Translational Modification-Dependent Activity of Matrix Metalloproteinases. Int. J. Mol. Sci. 2019, 20, 3077. [CrossRef]

8. Ricarte-Bratti, J.P.; Brizuela, N.Y.; Jaime-Albarran, N.; Montrull, H.L. IL-6, MMP 3 and prognosis in previously healthy sepsis patients. Rev. Fac. Cien. Med. Univ. Nac. Cordoba 2017, 74, 99-106. [CrossRef] [PubMed]

9. Lauhio, A.; Hästbacka, J.; Pettilä, V.; Tervahartiala, T.; Karlsson, S.; Varpula, T.; Varpula, M.; Ruokonen, E.; Sorsa, T.; Kolho, E. Serum MMP-8, -9 and TIMP-1 in sepsis: High serum levels of MMP-8 and TIMP-1 are associated with fatal outcome in a multicentre, prospective cohort study. Hypothetical impact of tetracyclines. Pharmacol. Res. 2011, 64, 590-594. [CrossRef] [PubMed]

10. Martin, G.; Asensi, V.; Montes, A.H.; Collazos, J.; Álvarez, V.A.; Carton, J.A.; Taboada, F.; Valle-Garay, E. Role of plasma matrix-metalloproteases (MMPs) and their polymorphisms (SNPs) in sepsis development and outcome in ICU patients. Sci. Rep. 2014, 4, 5002. [CrossRef]

11. Fiotti, N.; Altamura, N.; Moretti, M.; Wassermann, S.; Zacchigna, S.; Farra, R.; Dapas, B.; Consoloni, L.; Giacca, M.; Grassi, G.; et al. Short Term Effects of Doxycycline on Matrix Metalloproteinases 2 and 9. Cardiovasc. Drugs Ther. 2008, 23, 153-159. [CrossRef] 
12. Maitra, S.R.; Jacob, A.; Zhou, M.; Wang, P. Modulation of matrix metalloproteinase-9 and tissue inhibitor of matrix metalloproteinase-1 in sepsis. Int. J. Clin. Exp. Med. 2010, 3, 180-185. [PubMed]

13. Fingleton, B. Matrix metalloproteinases as regulators of inflammatory processes. Biochim. Biophys. Acta BBA Bioenerg. 2017, 1864, 2036-2042. [CrossRef]

14. Rutter, J.; Mitchell, T.I.; Butticè, G.; Meyers, J.; Gusella, J.F.; Ozelius, L.J.; Brinckerhoff, C.E. A single nucleotide polymorphism in the matrix metalloproteinase-1 promoter creates an Ets binding site and augments transcription. Cancer Res. 1998, 58, 5321-5325. [PubMed]

15. Ong, C.; Elkington, P.; Brilha, S.; Ugarte-Gil, C.; Esteban, M.T.T.; Tezera, L.B.; Pabisiak, P.J.; Moores, R.C.; Sathyamoorthy, T.; Patel, V.; et al. Neutrophil-Derived MMP-8 Drives AMPK-Dependent Matrix Destruction in Human Pulmonary Tuberculosis. PLoS Pathog. 2015, 11, e1004917. [CrossRef] [PubMed]

16. Borghaei, R.C.; Gorski, G.; Javadi, M. NF- $\mathrm{kB}$ and ZBP-89 regulate MMP-3 expression via a polymorphic site in the promoter. Biochem. Biophys. Res. Commun. 2009, 382, 269-273. [CrossRef]

17. Mearelli, F.; Fiotti, N.; Giansante, C.; Casarsa, C.; Orso, D.; De Helmersen, M.; Altamura, N.; Ruscio, M.; Castello, L.M.; Colonetti, E.; et al. Derivation and Validation of a Biomarker-Based Clinical Algorithm to Rule Out Sepsis From Noninfectious Systemic Inflammatory Response Syndrome at Emergency Department Admission. Crit. Care Med. 2018, 46, 1421-1429. [CrossRef] [PubMed]

18. Mearelli, F.; Barbati, G.; Casarsa, C.; Giansante, C.; Breglia, A.; Spica, A.; Moras, C.; Olivieri, G.; Occhipinti, A.A.; De Nardo, M.; et al. The Integration of qSOFA with Clinical Variables and Serum Biomarkers Improves the Prognostic Value of qSOFA Alone in Patients with Suspected or Confirmed Sepsis at ED Admission. J. Clin. Med. 2020, 9, 1205. [CrossRef]

19. Levy, M.M.; Fink, M.P.; Marshall, J.C.; Abraham, E.; Angus, D.; Cook, D.; Cohen, J.; Opal, S.M.; Vincent, J.-L.; Ramsay, G. 2001 SCCM/ESICM/ACCP/ATS/SIS International Sepsis Definitions Conference. Intensive Care Med. 2003, 29, 530-538. [CrossRef]

20. Fiotti, N.; Deiuri, E.; Altamura, N.; De Colle, P.; Moretti, M.; Toigo, G.; Giansante, C. Body composition and muscular strength changes after moderate activity: Association with matrix metalloproteinase polymorphisms. Arch. Gerontol. Geriatr. 2009, 49, 83-94. [CrossRef]

21. Fiotti, N.; Altamura, N.; Fisicaro, M.; Carraro, N.; Uxa, L.; Grassi, G.; Torelli, L.; Gobbato, R.; Guarnieri, G.; Baxter, B.T.; et al. MMP-9 Microsatellite Polymorphism and Susceptibility to Carotid Arteries Atherosclerosis. Arter. Thromb. Vasc. Biol. 2006, 26, 1330-1336. [CrossRef] [PubMed]

22. Lorente, L.; Martín, M.; Plasencia, F.; Solé-Violán, J.; Blanquer, J.; Labarta, L.; Díaz, C.; Borreguero-León, J.M.; Jiménez, A.; Páramo, J.A.; et al. The 372 T/C genetic polymorphism of TIMP-1 is associated with serum levels of TIMP-1 and survival in patients with severe sepsis. Crit. Care 2013, 17, R94. [CrossRef] [PubMed]

23. Solé, X.; Guinó, E.; Valls, J.; Iniesta, R.; Moreno, V. SNPStats: A web tool for the analysis of association studies. Bioinformatics 2006, 22, 1928-1929. [CrossRef] [PubMed]

24. Culej, J.; Gabaj, N.; Štefanović, M.; Karlović, D. Prediction of schizophrenia using MAOA-uVNTR polymorphism: A case-control study. Indian J. Psychiatry 2020, 62, 80-86. [CrossRef] [PubMed]

25. Horita, N.; Kaneko, T. Genetic model selection for a case-control study and a meta-analysis. Meta Gene 2015, 5, 1-8. [CrossRef]

26. Kong, M.Y.; Gaggar, A.; Li, Y.; Winkler, M.; Blalock, J.E.; Clancy, J. Matrix Metalloproteinase Activity in Pediatric Acute Lung Injury. Int. J. Med Sci. 2009, 6, 9-17. [CrossRef] [PubMed]

27. Fu, Q.; Yu, W.; Fu, S.; Chen, E.; Zhang, S.; Liang, T.-B. Screening and identification of key gene in sepsis development. Medicine 2020, 99, e20759. [CrossRef] [PubMed]

28. Tester, A.M.; Cox, J.H.; Connor, A.R.; Starr, A.E.; Dean, R.A.; Suarez-Puente, X.; López-Otín, C.; Overall, C.M. LPS Responsiveness and Neutrophil Chemotaxis In Vivo Require PMN MMP-8 Activity. PLoS ONE 2007, 2, e312. [CrossRef]

29. Quintero, P.A.; Knolle, M.D.; Cala, L.F.; Zhuang, Y.; Owen, C.A. Matrix Metalloproteinase-8 Inactivates Macrophage Inflammatory Protein-1 $\alpha$ To Reduce Acute Lung Inflammation and Injury in Mice. J. Immunol. 2009, 184, 1575-1588. [CrossRef]

30. Bhowmick, M.; Tokmina-Roszyk, D.; Onwuha-Ekpete, L.; Harmon, K.; Robichaud, T.; Fuerst, R.; Stawikowska, R.; Steffensen, B.; Roush, W.; Wong, H.R.; et al. Second Generation Triple-Helical Peptide Inhibitors of Matrix Metalloproteinases. J. Med. Chem. 2017, 60, 3814-3827. [CrossRef]

31. Djurić, T.; Stanković, A.; Končar, I.; Radak, D.; Davidović, L.; Alavantić, D.; Živković, M. Association of MMP-8 promoter gene polymorphisms with carotid atherosclerosis: Preliminary study. Atherosclerosis 2011, 219, 673-678. [CrossRef] [PubMed]

32. Pradhan-Palikhe, P.; Pussinen, P.; Vikatmaa, P.; Palikhe, A.; Kivimäki, A.S.; Lepäntalo, M.; Salo, T.; Sorsa, T. Single nucleotide polymorphism $-799 \mathrm{C} / \mathrm{T}$ in matrix metalloproteinase-8 promoter region in arterial disease. Innate Immun. 2011, 18, 511-517. [CrossRef] [PubMed]

33. Feng, J.; Chen, Y.; Hua, W.; Sun, X.; Chen, Y.; Liu, Y.; Fan, J.; Zhao, Y.; Zhao, L.; Xu, X.; et al. The MMP-8 rs11225395 Promoter Polymorphism Increases Cancer Risk of Non-Asian Populations: Evidence from a Meta-Analysis. Biomolecules $2019,9,570$. [CrossRef]

34. Tai, J.; Sun, D.; Wang, X.; Kang, Z. Matrix metalloproteinase-8 rs11225395 polymorphism correlates with colorectal cancer risk and survival in a Chinese Han population: A case-control study. Aging 2020, 12, 19618-19627. [CrossRef] [PubMed]

35. Li, W.; Wang, X.; Tian, Y.; Xu, L.; Zhang, L.; Shi, D.; Feng, X.; Lu, R.; Meng, H. A novel multi-locus genetic risk score identifies patients with higher risk of generalized aggressive periodontitis. J. Periodontol. 2019, 91, 925-932. [CrossRef] 
36. Park, H.S.; Ko, K.H.; Kim, J.O.; An, H.J.; Kim, Y.R.; Kim, J.H.; Lee, W.S.; Kim, N.K. Association Study between the Polymorphisms of Matrix Metalloproteinase (MMP) Genes and Idiopathic Recurrent Pregnancy Loss. Genes 2019, 10, 347. [CrossRef]

37. Collazos, J.; Asensi, V.; Martin, G.; Montes, A.H.; Suárez-Zarracina, T.; Valle-Garay, E. The effect of gender and genetic polymorphisms on matrix metalloprotease (MMP) and tissue inhibitor (TIMP) plasma levels in different infectious and non-infectious conditions. Clin. Exp. Immunol. 2015, 182, 213-219. [CrossRef] [PubMed]

38. Chen, B.; Cole, J.W.; Grond-Ginsbach, C. Departure from Hardy Weinberg Equilibrium and Genotyping Error. Front. Genet. 2017, 8, 167. [CrossRef]

39. Rella, J.M.; Jilma, B.; Fabry, A.; Kaynar, A.M.; Mayr, F.B. MMP-8 Genotypes Influence the Inflammatory Response in Human Endotoxemia. Inflammation 2013, 37, 451-456. [CrossRef] [PubMed]

40. Miyamoto, H.; Ogawa, M.; Maruta, K.; Nikaido, Y.; Yamamoto, C.; Taniguchi, H.; Yoshida, S.-I. Temperature Effects onLegionella pneumophilaKilling by and Multiplication in Phagocytes of Guinea Pigs. Microbiol. Immunol. 1995, 39, 647-654. [CrossRef]

41. Fröhlich, D.; Wittmann, S.; Rothe, G.; Sessler, D.I.; Vogel, P.; Taeger, K. Mild Hyperthermia Down-Regulates Receptor-Dependent Neutrophil Function. Anesthesia Analg. 2004, 99, 284-292. [CrossRef]

42. Mukhin, Y.V.; Gooz, M.; Raymond, J.R.; Garnovskaya, M.N. Collagenase-2 and -3 Mediate Epidermal Growth Factor Receptor Transactivation by Bradykinin B2Receptor in Kidney Cells. J. Pharmacol. Exp. Ther. 2006, 318, 1033-1043. [CrossRef]

43. Methner, C.; Donat, U.; Felix, S.B.; Krieg, T. Cardioprotection of bradykinin at reperfusion involves transactivation of the epidermal growth factor receptor via matrix metalloproteinase-8. Acta Physiol. 2009, 197, 265-271. [CrossRef]

44. Kornspan, J.D.; Tarshis, M.; Rottem, S. Invasion of Melanoma Cells by Mycoplasma hyorhinis: Enhancement by Protease Treatment. Infect. Immun. 2010, 78, 611-617. [CrossRef]

45. Borchsenius, S.N.; Daks, A.; Fedorova, O.; Chernova, O.; Barlev, N.A. Effects of mycoplasma infection on the host organism response via p53/NF-кB signaling. J. Cell. Physiol. 2018, 234, 171-180. [CrossRef]

46. Miwa, K.; Nakashima, H.; Aoki, M.; Miyake, T.; Kawasaki, T.; Iwai, M.; Oishi, M.; Kataoka, K.; Ohgi, S.; Ogihara, T.; et al. Inhibition of ets, an essential transcription factor for angiogenesis, to prevent the development of abdominal aortic aneurysm in a rat model. Gene Ther. 2005, 12, 1109-1118. [CrossRef]

47. De Siervi, A.; De Luca, P.; Moiola, C.P.; Gueron, G.; Tongbai, R.; Chandramouli, G.V.R.; Haggerty, C.; Dzekunova, I.; Petersen, D.; Kawasaki, E.; et al. Identification of new Rel/NFkB regulatory networks by focused genome location analysis. Cell Cycle 2009, 8, 2093-2100. [CrossRef] [PubMed]

48. Krüll, M.; Klucken, A.C.; Wuppermann, F.N.; Fuhrmann, O.; Magerl, C.; Seybold, J.; Hippenstiel, S.; Hegemann, J.H.; Jantos, C.A.; Suttorp, N. Signal transduction pathways activated in endothelial cells following infection with Chlamydia pneumoniae. J. Immunol. 1999, 162, 4834-4841. [PubMed]

49. Wang, H.; Lu, J.; Li, K.; Ren, H.; Shi, Y.; Qin, T.; Duan, X.; Fang, M. The virulence of Legionella pneumophila is positively correlated with its ability to stimulate NF-кB activation. Futur. Microbiol. 2018, 13, 1247-1259. [CrossRef] [PubMed]

50. Zhu, C.; Odeberg, J.; Hamsten, A.; Eriksson, P. Allele-specific MMP-3 transcription under in vivo conditions. Biochem. Biophys. Res. Commun. 2006, 348, 1150-1156. [CrossRef] [PubMed]

51. Lichtinghagen, R.; Bahr, M.; Wehmeier, M.; Michels, D.; Haberkorn, C.I.; Arndt, B.; Flemming, P.; Manns, M.P.; Boeker, K.H.W Expression and coordinated regulation of matrix metalloproteinases in chronic hepatitis $\mathrm{C}$ and hepatitis $\mathrm{C}$ virus-induced liver cirrhosis. Clin. Sci. 2003, 105, 373-382. [CrossRef] [PubMed]

52. Eser, B.; Eser, O.; Yuksel, Y.; Aksit, H.; Karavelioglu, E.; Tosun, M.; Sekerci, Z. Effects of MMP-1 and MMP-3 gene polymorphisms on gene expression and protein level in lumbar disc herniation. Genet. Mol. Res. 2016, 15. [CrossRef] [PubMed]

53. Schuurhof, A.; Bont, L.; Hodemaekers, H.M.; De Klerk, A.; De Groot, H.; Hofland, R.W.; Van De Pol, A.C.; Kimpen, J.L.L.; Janssen, R. Proteins involved in extracellular matrix dynamics are associated with respiratory syncytial virus disease severity. Eur. Respir. J. 2012, 39, 1475-1481. [CrossRef] [PubMed]

54. Lan, Y.-Y.; Yeh, T.-H.; Lin, W.-H.; Wu, S.-Y.; Lai, H.-C.; Chang, F.-H.; Takada, K.; Chang, Y. Epstein-Barr Virus Zta Upregulates Matrix Metalloproteinases 3 and 9 That Synergistically Promote Cell Invasion In Vitro. PLoS ONE 2013, 8, e56121. [CrossRef] [PubMed]

55. Shi, S.; Su, M.; Shen, G.; Hu, Y.; Yi, F.; Zeng, Z.; Zhu, P.; Yang, G.; Zhou, H.; Li, Q.; et al. Matrix metalloproteinase 3 as a valuable marker for patients with COVID-19. J. Med Virol. 2020, 93, 528-532. [CrossRef] [PubMed]

56. Shankavaram, U.T.; DeWitt, D.L.; Wahl, L.M. Lipopolysaccharide induction of monocyte matrix metalloproteinases is regulated by the tyrosine phosphorylation of cytosolic phospholipase A2. J. Leukoc. Biol. 1998, 64, 221-227. [CrossRef]

57. Pugin, J.; Widmer, M.-C.; Kossodo, S.; Liang, C.-M.; Preas, H.L.; Suffredini, A.F. Human Neutrophils Secrete Gelatinase BIn VitroandIn Vivoin Response to Endotoxin and Proinflammatory Mediators. Am. J. Respir. Cell Mol. Biol. 1999, 20, 458-464. [CrossRef] [PubMed]

58. Pagenstecher, A.; Stalder, A.K.; Kincaid, C.L.; Volk, B.; Campbell, I.L. Regulation of Matrix Metalloproteinases and Their Inhibitor Genes in Lipopolysaccharide-Induced Endotoxemia in Mice. Am. J. Pathol. 2000, 157, 197-210. [CrossRef]

59. Singh, B.; Fleury, C.; Jalalvand, F.; Riesbeck, K. Human pathogens utilize host extracellular matrix proteins laminin and collagen for adhesion and invasion of the host. FEMS Microbiol. Rev. 2012, 36, 1122-1180. [CrossRef] 